\title{
Sensibilidade de Diferentes ACessos de Egeria najas E Egeria densa aOs Herbicidas DiQuAT E FluRIDONE ${ }^{1}$
}

\author{
Sensitivity of Different Accesses of Egeria najas and Egeria densa to the Herbicides Diquat and \\ Fluridone
}

\begin{abstract}
MARTINS, D. ${ }^{2}$, TRIGUEIRO, L.R.C. ${ }^{3}$, DOMINGOS, V.D. ${ }^{4}$, TERRA, M.A. ${ }^{3}$ e COSTA, N.V. ${ }^{4}$
RESUMO - O surgimento de novos genótipos de plantas daninhas aquáticas pertencentes ao gênero Egeria motivou a realização deste estudo, o qual teve como objetivo avaliar o comportamento de diferentes acessos das espécies de E. densa e E. najas em relação ao tratamento com os herbicidas diquat e fluridone. Foram avaliados acessos de diferentes biótipos de E. densa provindos dos reservatórios de Jupiá, Nova Avanhandava, Promissão e Salto Grande e de E. najas oriundos de Jupiá, Três Irmãos, Ilha Solteira e Ibitinga. O delineamento experimental adotado foi o inteiramente casualizado com cinco repetições. Os tratamentos e concentrações utilizados no estudo com E. densa e E. najas foram: diquat (Reward $240 \mathrm{~g} \mathrm{~L}^{-1}$ ) a 0,5 e $1,0 \mathrm{mg} \mathrm{L}^{-1}$ com reaplicação aos 12 dias após a primeira aplicação, e a concentração de fluridone mantida entre 3 e $20 \mathrm{mg} \mathrm{L}^{-1}$, além de uma testemunha sem aplicação de herbicidas. As duas espécies foram controladas de forma eficiente pelo herbicida diquat com uma ou duas aplicações, sendo ambas as concentrações eficientes, porém observaram-se respostas diferenciadas dos acessos estudados às concentrações do herbicida. Para o herbicida fluridone, as espécies e acessos estudados comportaram-se também de forma diferenciada em relação à ação do herbicida, ocorrendo acessos desde mediana a altamente suscetiveis em ambas as espécies.
\end{abstract}

Palavras-chave: planta aquática, planta daninha, biótipo, Hydrocaritaceae, controle químico.

\begin{abstract}
The occurrence of new aquatic weed genotypes belonging to the Egeria genus led to the development of this work, aimed to evaluate the behavior of different accesses of $\boldsymbol{E}$. densa and $\boldsymbol{E}$. najas in response to treatment with the herbicides diquat and fluridone. Accesses of different E. densa biotypes from Jupiá, Nova, Avanhandava, Promissão and Salto Grande reservoirs and of different E. najas biotypes from Jupia, Três irmãos, Ilha Solteira and Ibitinga reservoirs were evaluated. The experiment was arranged in a randomized complete design with five replications. The treatments and concentrations used in the $\boldsymbol{E}$. densa and $\boldsymbol{E}$. najas studies were: diquat (Reward $240 \mathrm{~g} \mathrm{~L}^{-1}$ ) at 0.5 and $1.0 \mathrm{mg} \mathrm{L}^{-1}$ with reapplication 12 days after the first application, with fluridone concentration maintained between 3 and $20 \mathrm{mg} \mathrm{L}^{-1}$, and a control without herbicide application. Both species were efficiently controlled by one or two applications of diquat, with both concentrations being efficient; however, the accesses studied presented a differentiated response to the herbicide concentrations. The species and accesses studied also behaved in a differentiated way in response to fluridone action, with medium to highly susceptible accesses occurring in both species.
\end{abstract}

Keywords: aquatic plant, weeds, biotype, Hydrocaritaceae, chemical control.

Recebido para publicação em 16.1.2007 e na forma revisada em 17.4.2007.

2 Professor Livre Docente, Dep. de Produção Vegetal, FCA-UNESP, C.P. 237, 18603-970, Botucatu, SP, Brasil.

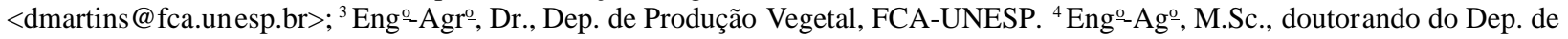
Produção Vegetal, FCA-UNESP. 


\section{INTRODUÇÃO}

O estado trófico de rios e lagos tem sido alterado principalmente pelo influxo de nutrientes provenientes do despejo de esgotos urbanos e industriais. Em conseqüência, nessas condições ambientais ocorre o crescimento excessivo de plantas aquáticas, o que resulta em inúmeros problemas relacionados à qualidade da água, bem como aos seus usos múltiplos. Dentre os diversos problemas causados pela presença dessas plantas, podem ser citados a obstrução de turbinas e grades de proteção, o funcionamento anormal de eclusas, os danos ao ambiente, entraves à navegação, abrigo de vetores de várias doenças, além de prejudicar atividades de lazer (Burkhalter, 1975; Pitelli, 1998; Carvalho et al., 2005).

Algumas espécies submersas pertencentes à familia Hydrocharitaceae apresentam alta similaridade morfológica, como Egeria densa, E. najas, Elodea canadensis, Elodea nuttallii, Hydrilla verticillata e Lagarosiphon major, de acordo com vários pesquisadores (Solymosy \& Gangstad, 1974; Cook \& Urmi-König, 1984; Yeo et al., 1984; Bowmer et al., 1995; Hoyer et al., 1996). O gênero Egeria é composto apenas por duas espécies, E. densa e E. najas, as quais são muito semelhantes entre si, perenes, submersas (enraizadas), nativas do Brasil e se propagam sobretudo por fragmentos do caule e, ocasionalmente, por sementes (Lorenzi, 2000; Kissmann, 1997; Cook \& Urmi-König, 1984). Assim, embora a reprodução sexuada seja pouco freqüente nessas espécies, deve-se ressaltar essa via de reprodução como uma das fontes de variação genética (Cook \& Urmi-König, 1984; Kissmann, 1997; Mori et al., 1999).

Quanto às alternativas de manejo de plantas daninhas aquáticas, tem-se destacado o uso de herbicidas, principalmente quando o alvo é constituído por espécies que se reproduzem vegetativamente, uma vez que o controle mecânico poderia ser um veículo de dispersão. Haller (1998) ressaltou que existem apenas seis herbicidas registrados para controle químico de plantas daninhas aquáticas nos Estados Unidos: 2,4-D, diquat, cobre, endothall, fluridone e glyphosate, sendo mais recentemente utilizado o herbicida triclopyr (Netherland \& Getsinger, 1992; Sprecher et al., 1998). No Brasil, o controle químico tem motivado a realização de diversas pesquisas com os herbicidas diquat e fluridone, aplicados principalmente no controle de E. densa e E. najas, bem como em outras espécies, como Eichhornia crassipes, Salvinia auriculata e Pistia stratiotes, no caso do diquat e imazapyr, os quais objetivam a redução do seu desenvolvimento ou mesmo a sua eliminação (Cardoso, 2001; Tanaka et al., 2001; Martins et al., 2003; Carvalho et al., 2003).

No primeiro estudo realizado, em condições de campo, com o fluridone, Marcondes et al. (2002) concluíram que a exposição contínua a concentrações desse herbicida entre 2,79 e $26,2 \mathrm{ug} \mathrm{L}^{-1}$ por um período de 130 dias, na lagoa denominada Flórida, pertencente ao rio Tietê, reduziu significativamente a biomassa e permitiu atingir niveis de controle de Egeria densa e Egeria najas superiores a 98,3\%.

Contudo, a eficiência do controle químico depende indiretamente da variabilidade genética da espécie, uma vez que o comportamento de cada genótipo poderá ser expresso de forma distinta à do tratamento herbicida.

A diversidade genética de plantas e a distribuição espacial são influenciadas por várias características da história de vida da espécie, assim como pelo modo de vida, seleção e mecanismos de dispersão (Hamrick \& Godt, 1996). Dessa forma, a reprodução sexuada está associada à recombinação genética, a qual promove a contínua emergência de novos genótipos (clones) e evita a perda de diversidade clonal e variação genética da população causada pela seleção natural e deriva genética (Hangelbroek et al., 2002).

A origem e dispersão das plantas daninhas tem sido alvo de algumas pesquisas, as quais utilizaram marcadores moleculares pelo método RAPD com resultados promissores em diversas espécies de plantas aquáticas, como $H$. verticilata, E. densa, E. canadensis e E. crassipes (Ryan, 1993 a, b; Weiss, 1997; Cardoso et al., 2002).

Mori et al. (1999) relataram que o represamento das águas do rio Tietê para geração de energia elétrica condicionou alterações no comportamento de colonização das espécies de Egeria no leito do rio, resultando em grandes populações de plantas dentro do reservatório de Jupiá no rio Tietê e em seus rios afluentes. 
Constataram, também, que o método RAPD foi eficaz na elucidação da variação genética em espécies de Egeria. O acúmulo dessa variabilidade no local foi resultante de possiveis cruzamentos entre genótipos diferentes.

Em acessos de Egeria coletados em reservatórios de São Paulo, tanto para E. densaquanto para $E$. najas foram encontradas diversidades genéticas, as quais foram maiores entre as populações de E. najas dos reservatórios de Três Irmãos e Jupiá. Ressalta-se que E. densa foi considerada a espécie mais variável geneticamente, em razão da maior porcentagem de locos polimórficos (Martins et al., 2003).

Assim, as diferenças genéticas encontradas entre os acessos de $E$. densa e $E$. najas coletados nos reservatórios do Estado de São Paulo subsidiaram a realização do presente estudo, em que se objetivou avaliar a sensibilidade desses diferentes biótipos aos herbicidas diquat e fluridone.

\section{MATERIAL E MÉTODOS}

O estudo foi realizado no Núcleo de Pesquisas Avançadas em Matologia (NUPAM) do Departamento de Produção Vegetal, FCA/ UNESP, campus de Botucatu. Acessos de E. densa denominados de Jupiá 1, Jupiá 2, Nova Avanhandava, Promissão e Salto Grande e os acessos de E. najas identificados como Jupiá, Três Irmãos, Ilha Solteira e Ibitinga foram selecionados em estudos prévios de variabilidade genética, nos quais foi utilizada a técnica RAPD, com o intuito de identificar os diferentes biótipos para representar as populações presentes em seus respectivos reservatórios (Martins et al., 2003).

Para este trabalho foram instalados quatro tratamentos, e para cada espécie testada ( $E$. densa e E. najas) utilizaram-se dois herbicidas (diquat e fluridone). As plantas referentes aos acessos foram repicadas com $20 \mathrm{~cm}$ de comprimento e cultivadas em vasos com solo de várzea, os quais foram acondicionados em caixas - d'água de fibra de vidro com capacidade de $300 \mathrm{~L}$ (0,60 m de diâmetro por 1,1 m de profundidade).

O delineamento experimental adotado foi o inteiramente casualizado, com cinco repetições. Apenas os estudos com diquat foram analisados em um esquema fatorial $2 \times 4$ para $E$. najas e $2 \times 5$ para E. densa, sendo duas concentrações de diquat e quatro e cinco acessos de plantas, respectivamente. Os tratamentos e concentrações utilizados no estudo com $E$. densa e E. najas foram: diquat (Reward $240 \mathrm{~g} \mathrm{~L}^{-1}$ ) a 0,5 e $1,0 \mathrm{mg} \mathrm{L}^{-1}$ e concentração de fluridone mantida entre 3 e $20 \mu \mathrm{g} \mathrm{L}^{-1}$ por um período de 110 dias, além de uma testemunha sem aplicação. $\mathrm{Na}$ época de aplicação, as plantas apresentavam 50 a $60 \mathrm{~cm}$ de comprimento da base até o ápice. A aplicação do herbicida diquat foi feita em duas épocas, com intervalo de 12 dias após a primeira aplicação, sendo mantidas as mesmas concentrações iniciais na reaplicação.

A manutenção da concentração do herbicida fluridone na água foi realizada utilizando método cromatográfico desenvolvido e validado no laboratório de Matologia da Faculdade de Ciências Agronômicas da Unesp, campus de Botucatu-SP, sendo necessárias nove reaplicações do herbicida, as quais sempre foram efetuadas quando sua concentração na água se encontrava entre 3 e $5 \mu \mathrm{g} \mathrm{L}^{-1} \mathrm{e}$, assim, elevava-se até $20 \mu \mathrm{g} \mathrm{L}^{-1}$. No método analítico utilizouse extração em fase sólida, com posterior eluição e concentração do fluridone das amostras e quantificação por CLAE (cromatografia líquida de alta eficiência). O método apresenta recuperação média de $94,9 \%$, incerteza inferior a $2 \%$ para a faixa de concentração testada e limite de determinação de $50 \mathrm{ng} \mathrm{L}^{-1}$ (Marcondes et al., 2002).

As avaliações visuais de controle para o herbicida diquat foram realizadas aos 10, $17 \mathrm{e}$ 25 dias após a aplicação (DAA) e, para o fluridone, aos 90 e 110 DAA, com o uso de uma escala percentual de notas, na qual zero referiase a nenhum controle e $100 \%$ ao controle total das plantas. As avaliações foram feitas até o desaparecimen to ou estabilização dos sintomas causados pelos herbicidas. Também foi utilizada uma terminologia técnica para classificar o controle das plantas daninhas aquáticas que possuem reprodução vegetativa, o qual foi denominado de insatisfatório (menor que $40 \%$ ), regular (41 a $75 \%$ ) e excelente $(76$ a $100 \%)$.

A análise de variância foi efetuada pelo teste $\mathrm{F}$, e as médias dos tratamentos, comparadas pelo teste " $\mathrm{t}$ " a $5 \%$. 


\section{RESULTADOS E DISCUSSÃO}

A porcentagem de controle proporcionada pelo herbicida diquat em plantas de E. densa, referente a diferentes acessos, está apresentada na Tabela 1. Observou-se que houve interação significativa entre os diferentes acessos e concentrações do herbicida diquat. Aos 10 DAA do herbicida diquat, verificou-se que o acesso Jupiá 2 foi mais sensível à concentração de $0,5 \mathrm{mg} \mathrm{L}^{-1}$ em relação aos demais locais, enquanto o controle variou entre ineficiente e regular. Os sintomas de fitointoxicação foram mais expressivos quando foi aplicada a concentração de $1,0 \mathrm{mg} \mathrm{L}^{-1}$, principalmente em relação às plantas do acesso Nova Avanhandava, que foi considerado o biótipo mais sensivel à ação do herbicida diquat, o que propiciou controle entre regular e excelente. Ressalta-se que houve inversão de respostas das plantas em relação às concentrações, uma vez que os acessos de Jupiá foram mais tolerantes à concentração de $1,0 \mathrm{mg} \mathrm{L}^{-1}$, e, na menor concentração, Jupiá 2 expressou maior sensibilidade. Portanto, o aumento da tolerância das plantas à concentração de $1,0 \mathrm{mg} \mathrm{L}^{-1}$ do herbicida diquat talvez possa ser devido ao fato de elas apresentarem limite de absorção de moléculas, que na maior concentração pode ter excedido essa capacidade de absorção das plantas.

Devido a rebrotas em todos os acessos estudados, em especial nos de Jupiá, realizou-se aos 12 DAA do herbicida diquat uma reaplicação das mesmas concentrações iniciais de diquat utilizadas em todos os acessos de Egeria analisados (Tabelas 1 e 2). Assim, já aos 17 DAA, os sintomas de injúria provocados pelo herbicida diquat foram mais severos, o que resultou em controle acima de $90 \%$, exceto para Jupiá 2 em ambas as concentrações testadas; a morte das plantas ocorreu apenas uma semana mais tarde, aos 25 DAA inicial do herbicida, em ambas as concentraçãos testadas.

Gangstad (1978) relatou que a aplicação da mistura de sulfato de cobre hidratado e diquat em $H$. verticilata aumentou a eficiência do herbicida já aos 14 DAA nas concentrações de 0,5 e 1,0 $\mathrm{mg} \mathrm{L}^{-1}$ de diquat, o que propiciou controles de 72 e $90 \%$ e, na ausência de sulfato de cobre hidratado, de 53 e $65 \%$, respectivamente, demonstrando assim, por esta espécie, que a mistura é necessária para melhorar a eficiência do controle

Em outros estudos, a adição de cobre ou sulfato de cobre tem sido recomendada, pois resultou em maior eficiência no controle em relação ao uso individual de diquat; ainda, essa mistura possui a vantagem de inibir o crescimento de algas. Ressalta-se que existem diferenças marcantes quanto à resposta a herbicidas por parte das espécies da família Hydrocaritaceae, pois no caso das espécies de Egeria a mistura com outros compostos não foi necessária para atribuir controles considerados satisfatórios.

Aos 17 DAA, os acessos de Jupiá apresentaram maior sensibilidade à concentração de $0,5 \mathrm{mg} \mathrm{L}^{-1}$ de diquat quando comparada à maior concentração aplicada; portanto, embora esse resultado seja contrário ao comportamento concentração-resposta esperado, considerou-se a hipótese de a maior concentração do herbicida diquat ter excedido a capacidade de absorção pelas plantas dos acessos de Jupiá (Tabela 1).

De maneira geral, verificou-se que as plantas de E. najas foram mais sensiveis em relação às de E. densa, uma vez que os sintomas de fitotoxicidade observados aos 10 DAA foram mais expressivos em relação à primeira espécie analisada, além do fato de o encerramento do estudo ter ocorrido de forma mais precoce, aos 17 DAA (Tabela 2). Aos 10 DAA, verifica-se que o herbicida diquat aplicado na menor concentração $\left(0,5 \mathrm{mg} \mathrm{L}^{-1}\right)$ foi mais eficaz sobre os acessos de E. najas, exceto para o acesso de Jupiá, porém com controle considerado bom. Já a maior concentração $\left(1,0 \mathrm{mg} \mathrm{L}^{-1}\right)$ propiciou controles que variaram de regular a excelente, e nenhum dos acessos atingiu controle total. Ressalta-se que as plantas do acesso de Ibitinga foram mais tolerantes quando submetidas à maior concentração do herbicida diquat. A tolerância ao herbicida diquat observada nos acessos de Ibitinga talvez possa ser explicada pela maior variabilidade genética $(82,7 \%$ de locos polimórficos) desse acesso em relação aos demais, constatado por Martins et al. (2003); assim, essa amplitude na variação genética aumenta a probabilidade do surgimento de genótipos tolerantes ao herbicida diquat. Contudo, aos 17 DAA observa-se que todos os acessos que receberam a concentração maior de diquat e o acesso Jupiá, que recebeu a concentração 
Tabela 1 - Porcentagem de controle de diferentes acessos de Egeria densa sob efeito do herbicida diquat. Botucatu-SP

\begin{tabular}{|c|c|c|c|c|c|c|}
\hline \multirow{4}{*}{ Acessos } & \multicolumn{6}{|c|}{ Porcent agem de controle (DAA) } \\
\hline & \multicolumn{2}{|c|}{10} & \multicolumn{2}{|c|}{$17^{1^{\prime}}$} & \multicolumn{2}{|c|}{25} \\
\hline & \multicolumn{6}{|c|}{ Concentração $\left(\mathrm{mg} \mathrm{L}^{-1}\right)$} \\
\hline & 0,5 & 1,0 & 0,5 & 1,0 & 0,5 & 1,0 \\
\hline Jupiá 1 & $26,8 \mathrm{~B} \mathrm{~b}$ & $43,0 \mathrm{D}$ a & $98,4 \mathrm{~A}$ a & $90,0 \mathrm{~B} \mathrm{~b}$ & 100,0 & 100,0 \\
\hline Jupiá 2 & $53,6 \mathrm{~A} \mathrm{a}$ & $47,0 \mathrm{D}$ a & $94,2 \mathrm{C} \mathrm{a}$ & $88,2 \mathrm{C} \mathrm{b}$ & 100,0 & 100,0 \\
\hline Nova Avanhandava & $32,0 \mathrm{D} \mathrm{b}$ & $89,0 \mathrm{~A} \mathrm{a}$ & $96,6 \mathrm{~B} \mathrm{~b}$ & $99,8 \mathrm{~A}$ a & 100,0 & 100,0 \\
\hline Promissão & $38,0 \mathrm{C} \mathrm{b}$ & $69,0 \mathrm{~B} \mathrm{a}$ & $96,6 \mathrm{~B} \mathrm{~b}$ & $99,6 \mathrm{~A} \mathrm{a}$ & 100,0 & 100,0 \\
\hline Salto Grande & $43,0 \mathrm{~B} \mathrm{~b}$ & $60,0 \mathrm{C} \mathrm{a}$ & $98,4 \mathrm{~A} \mathrm{a}$ & $98,4 \mathrm{~A} \mathrm{a}$ & 100,0 & 100,0 \\
\hline \multicolumn{7}{|l|}{$\mathrm{F}$} \\
\hline Acessos & \multicolumn{2}{|c|}{$6,57 *$} & \multicolumn{2}{|c|}{$32,70^{*}$} & \multicolumn{2}{|c|}{-} \\
\hline Concentrações & \multicolumn{2}{|c|}{$49,08 *$} & \multicolumn{2}{|c|}{$14,15^{*}$} & \multicolumn{2}{|c|}{-} \\
\hline Acessos x Concentrações & \multicolumn{2}{|c|}{$10,14 *$} & \multicolumn{2}{|c|}{$22,97 *$} & \multicolumn{2}{|c|}{-} \\
\hline $\mathrm{CV}(\%)$ & \multicolumn{2}{|c|}{23,10} & \multicolumn{2}{|c|}{1,80} & \multicolumn{2}{|c|}{-} \\
\hline d.m.s. Acessos & \multicolumn{2}{|c|}{4,35} & \multicolumn{2}{|c|}{1,68} & \multicolumn{2}{|c|}{-} \\
\hline d.m.s. Concentrações & \multicolumn{2}{|c|}{14,36} & \multicolumn{2}{|c|}{2,23} & \multicolumn{2}{|c|}{-} \\
\hline
\end{tabular}

* Significativo a $5 \%$ de probabilidade.

Médias seguidas de u ma mesma letra maiúscula, na coluna, e minúscula, na linha, não diferem estatisticamente entre si pelo teste $\mathrm{t}(\mathrm{P}>0,05)$.

DAA: dias após a aplicação.

${ }^{1 /}$ Reaplicação aos 12 DAA, com as mesmas concentrações iniciais aplicadas.

Tabela 2 - Porcentagem de controle de diferentes acessos de Egeria najas sob o efeito do herbicida diquat. Botucatu-SP

\begin{tabular}{|c|c|c|c|c|}
\hline \multirow{4}{*}{ Acess os } & \multicolumn{4}{|c|}{ Porcentagem de controle (DAA) } \\
\hline & \multicolumn{2}{|c|}{10} & \multicolumn{2}{|c|}{$17^{1^{\prime}}$} \\
\hline & \multicolumn{4}{|c|}{ Concentração $\left(\mathrm{mg} \mathrm{L}^{-1}\right)$} \\
\hline & 0,5 & 1,0 & 0,5 & 1,0 \\
\hline Três Irmãos & $100,0 \mathrm{~A} \mathrm{a}$ & $98,0 \mathrm{~A} \mathrm{ab}$ & 100,0 & 100,0 \\
\hline Ilha solteira & $100,0 \mathrm{~A} \mathrm{a}$ & $96,6 \mathrm{~A} \mathrm{~b}$ & 100,0 & 100,0 \\
\hline Jupiá & $86,4 \mathrm{~B} \mathrm{~b}$ & $98,8 \mathrm{~A} \mathrm{ab}$ & 100,0 & 100,0 \\
\hline Ibitinga & $100,0 \mathrm{~A} \mathrm{a}$ & $69,0 \mathrm{~A} \mathrm{a}$ & 100,0 & 100,0 \\
\hline \multicolumn{5}{|l|}{$\mathrm{F}$} \\
\hline Acessos & \multicolumn{2}{|c|}{$4,67 *$} & \multicolumn{2}{|c|}{-} \\
\hline Concen trações & \multicolumn{2}{|c|}{$1,29^{\mathrm{ns}}$} & \multicolumn{2}{|c|}{-} \\
\hline Acess os x Concentrações & \multicolumn{2}{|c|}{$5,53 * *$} & \multicolumn{2}{|c|}{-} \\
\hline $\mathrm{CV}(\%)$ & \multicolumn{2}{|c|}{5,0} & \multicolumn{2}{|c|}{ - } \\
\hline d.m.s. Acessos & \multicolumn{2}{|c|}{3,19} & \multicolumn{2}{|c|}{. } \\
\hline d.m.s. Concentrações & \multicolumn{2}{|c|}{8,49} & \multicolumn{2}{|c|}{-} \\
\hline
\end{tabular}

** Significativo a $1 \%$ de probabilidade.

* Significativo a $5 \%$ de probabilidade.

${ }^{\text {ns }}$ não-significativo.

Médias seguidas de uma mesma letra maiúscula, na coluna, e minúscula, na linha, não diferem estatisticamente entre si pelo teste $\mathrm{t}(\mathrm{P}>0,05)$.

DAA - dias após a aplicação.

${ }^{1 /}$ Reaplicação aos 12 DAA, com as mesmas concentrações iniciais aplicadas. 
menor após a reaplicação do herbicida aos 12 DAA, apresentaram controle total, com a morte de todas as plantas.

Quanto à resposta das plantas de E. densa em função das concentraçãos do herbicida fluridone (Tabela 3), constatou-se, aos 90 DAA, que os acessos Jupiá 1 e Nova Avanhandava expressaram maior sensibilidade ao herbicida fluridone, apresentando assim sintomas de toxicidade mais evidentes em suas plantas. McCorkelle et al. (1992, citado por Bowmer et al., 1995) ressaltaram que $E$. densa, bem como $E$. canadensis e $H$. verticillata, são altamente sensiveis ao herbicida fluridone. Entretanto, o longo período de contato requerido para a ação deste herbicida pode dificultar o manejo de controle quando aplicado em corpos hídricos de fluxo contínuo, o que desfavorece a absorção por reduzir, assim, o tempo de contato da molécula com a planta (Bowmer et al., 1995).

Já aos 110 DAA (Tabela 3), as plantas referentes aos acessos Jupiá 1 e Nova Avanhandava expressaram comportamento semelhante em relação aos demais locais, exceto para Jupiá 2 , que inicialmente poderia ser considerado um biótipo tolerante, porém, ao final das avaliações, foi o mais sensivel à aplicação do herbicida fluridone. Esses resultados corroboram parcialmente os obtidos por Marcondes et al. (2002) em um estudo sob condições de campo, os quais condicionaram as plantas de E. densa e $E$. najas a contínuas exposições ao herbicida fluridone em concentrações que variaram de 2,79 a $26,2 \mathrm{ug} \mathrm{L}^{-1}$ por um período de 130 dias, em uma lagoa marginal do rio Tietê denominada Flórida, o que resultou em expressiva redução da biomassa e niveis de controle superiores a 98,3\%. Entretanto, no presente estudo o controle das plantas de $E$. densa foi considerado regular a bom; talvez essas respostas diferentes entre os genótipos possam ser explicadas pela variabilidade genética existente entre estes ou por variantes ou aspectos relacionados a estudos de caixa-d'água.

$\mathrm{Na}$ Tabela 4, verifica-se que a intoxicação observada em plantas de E. najas aos 90 DAA devido à ação do herbicida fluridone confirmou a maior sensibilidade dessa espécie à ação de herbicidas, em relação às plantas de $E$. densa (Tabela 3). Todos os acessos de E. najas foram controlados de forma satisfatória, com exceção do acesso denominado de Ibitinga.
Tabela 3 - Porcentagem de controle de diferentes acessos de Egeria densa sob efeito do herbicida fluridone. Botucatu-SP

\begin{tabular}{|l|c|c|}
\hline \multirow{2}{*}{ Acessos } & \multicolumn{2}{|c|}{ Porcentagem de controle (DAA) } \\
\cline { 2 - 3 } & 90 & 110 \\
\hline Jupiá 1 & $44,2 \mathrm{a}$ & $81,8 \mathrm{~b}$ \\
\hline Jupiá 2 & $27,4 \mathrm{~b}$ & $90,0 \mathrm{a}$ \\
\hline Nova Avanhandava & $48,0 \mathrm{a}$ & $79,4 \mathrm{~b}$ \\
\hline Promissão & $11,4 \mathrm{c}$ & $76,2 \mathrm{~b}$ \\
\hline Salto Grande & $18,0 \mathrm{bc}$ & $75,2 \mathrm{~b}$ \\
\hline F de Acessos & $11,53^{*}$ & $6,75^{*}$ \\
\hline CV $(\%)$ & 35,3 & 6,3 \\
\hline d.m.s. & 13,87 & 6,71 \\
\hline
\end{tabular}

* Significativo a $5 \%$ de probabilidade.

Médias seguidas de uma mesma letra, na coluna, não diferem estatisticamente entre si pelo teste $t(P>0,05)$.

DAA - dias após a aplicação.

Tabela 4 - Porcentagem de controle dos diferentes acessos de Egeria najas sob efeito do herbicida fluridone. BotucatuSP

\begin{tabular}{|l|c|c|}
\hline \multirow{2}{*}{ Acessos } & \multicolumn{2}{|c|}{ Porcentagem de controle (DAA) } \\
\cline { 2 - 3 } & 90 & 110 \\
\hline Três Irmãos & $80,0 \mathrm{a}$ & $71,4 \mathrm{~b}$ \\
\hline Ilha solteira & $81,8 \mathrm{a}$ & $75,6 \mathrm{~b}$ \\
\hline Jupiá & $85,0 \mathrm{a}$ & $66,4 \mathrm{~b}$ \\
\hline Ibitinga & $51,2 \mathrm{~b}$ & $99,0 \mathrm{a}$ \\
\hline F de Acessos & $38,4 *$ & $14,8^{*}$ \\
\hline CV $(\%)$ & 7,6 & 10,8 \\
\hline d.m.s. & 7,58 & 11,26 \\
\hline
\end{tabular}

*Significativo a $5 \%$ de probabilidade.

Médias seguidas de uma mesma letra, na coluna, não diferem estatisticamente entre si pelo te ste $t(\mathrm{P}>0,05)$.

DAA - dias após a aplicação.

No entanto, no final do estudo, aos 110 DAA do herbicida fluridone, de forma oposta à observado anteriormente, apenas o acesso Ibitinga mostrou controle considerado eficiente; os demais acessos apresentaram controles considerados ineficientes (acesso de Jupiá) ou medianamente satisfatórios (acessos Três Irmãos e Ilha solteira). Ressalta-se que $E$. densa foi considerada a espécie mais variável geneticamente, em razão da maior porcentagem de 
locos polimórficos (Martins et al., 2003). Portanto, dentro dessa variação genética observada em maior proporção na espécie $E$. densa, houve maior probabilidade de haver genótipos mais tolerantes ao herbicida fluridone, o qual é de ação sistêmica. Tanaka (2001) relatou que $E$. densa mostrou-se mais tolerante ao herbicida fluridone em comparação às plantas de E. najas, em estudo realizado em condições de laboratório. O acesso de Ibitinga foi considerado o genótipo mais sensivel ao fluridone, o qual apresentou a maior porcentagem de locos polimórficos $(82,7 \%)$, bem como maior número de locos polimórficos (43\%), de acordo com estudo realizado por Martins et al. (2003). Essa amplitude de variação genética, pela recombinação dos genes, também pode ter favorecido o surgimento de um genótipo mais suscetivel à ação do herbicida fluridone.

Netherland et al. (2000) relataram os diferentes niveis de sensibilidade encontrados em $H$. verticillata no estado da Flórida, em relação ao tratamento com o herbicida fluridone. Verificaram que algumas populações mostravamse mais sensiveis a concentrações baixas do herbicida, como $2 \mu \mathrm{g} \mathrm{L} \mathrm{L}^{-1}$, enquanto outras populações não expressavam respostas similares a concentrações altas, como 10 a $20 \mu \mathrm{g} \mathrm{L}^{-1}$. Esse comportamento diferenciado observado em $H$. verticillata foi atribuído às aplicações sucessivas de fluridone, que podem ser consideradas como fator contribuinte ao incremento da tolerância ao herbicida nessas populações, como ora observado.

\section{LITERATURA CITADA}

BOWMER, K. H.; JACOBS, S. W. L.; SAINTY, G. R. Identification, biology and management of Elodea Canadensis, Hydrocharitaceae. J. Aquatic Plant Manag. v. 33, p. 13-19, 1995.

BURKHALTER, A. P. The State of Florida aquatic weed control program. In: Simposium on water quality and managemente through biological control, 1975,

Gainesville. Proceedings... Gainesville: 1975. p. 15-19.

CARDOSO, L. R. Sensibilidade de diferentes acessos de aguapé coletados em reserva tórios do estado de São Paulo a herbi cidas. 2001. 95 f. Dissertação (Mes trado em Agronomia) - Universidade Estadual Paulista, Botucatu, 2001.
CARVALHO, F. T. et al. Influência da turbidez da água do rio Tietê na ocorrência de plantas aquáticas. Planta Daninha, v. 23, n. 2, p. 359-362, 2005.

CARVALHO, F. T.; CAVENAGHI, A. L.; BRONHARA, A. A. Eficiência de fluridone no controle de plantas aquáticas submersas no reservatório de Jupiá. Planta Daninha, v. 21, p. 69-77, 2003.

COOK, C. D. K.; URMI-KÖNIG, K. A revision of the genus Egeria (Hydrocharitaceae). Aquatic Bot., v. 19, n. 1, p. 73-96, 1984.

GANGSTAD, E. O. Chemical control of Hydrilla. J. Aquatic Plant Manag., v. 16, p. 38- 40, 1978.

HANGELBROEK, H. H. et al. Clonal diversity and structure within a population of the pondweed Potamogeton pectinatus foraged by Bewick's swans. Molec. Ecol., v. 11, p. 2137-2 150, 2002.

HAMRICK, J. L.; GODT, M. J. W. Effects of life history traits on genetic diversity in plant species. Philos. Trans. Royal Soc. London, Series B: Biol. Sci., v. 351, p. 1291-1298, 1996.

HOGAN, W. D.; HOPKINS, S. B. Improved efficiency in aquatic vegetation control. In: ANNUAL MEETING OF THE SOUTHERN WEED SCIENCE SOCIETY, 31., 1978. Proceedings... 1978. 237 p. CD-ROM.

HOYER, M. V. et al. Florida freshwater plants: a handbook of common aquatic plants in Florida lakes. Gainesville: University of Florida, 1996. 264 p.

KISSMANN, K.G.; GROTH, D. Plantas infestantes e nocivas. 2. ed. São Paulo: 1997. Tomo I. 825 p.

LORENZI, H. Plantas daninhas do Brasil: terrestres, aquáticas, parasitas e tóxicas. 3. ed. Nova Odessa: Institu to Plantarum, 2000. 608 p.

MARTINS, D. et al. Caracterização genética de acessos de egéria (Egeria spp.) coletados no estado de São Paulo.

Planta Daninha, v. 21, p. 1-6, 2003.

MARCONDES, D. A. S. et al. Eficiência de fluridone no controle de plantas aquáticas e efeito sobre algumas características ambientais. Planta Daninha, v. 20, p. 6371, 2002.

MORI, E. S. et al. Caracterização genética de populações de Egeria najas presentes no reservatório de Jupiá e rios afluentes. Planta Daninha, v. 17, n. 2, p. 217-225, 1999.

MOSSLER, M. A. et al. A quality control standard for fluridone analysis. J. Aquatic Plant Manag., v. 33, p. 2324, 1995.

Planta Daninha, Viçosa-MG v. 25, n. 2, p. 351-358, 2007 
NETHERLAND, M. et al. Differential response of hydrilla to fluridone. In: AQUATIC PLANT MANAGEMENT SOCIETY, FORTIETH ANNUAL MEETING, 24., 2000. San Diego. Proc eedings... San Diego: 2000. p. 24.

NETHERLAND, M. D.; GETSINGER, K. D. Effic acy of triclopyr on Eurasian watermilfoil: concentration and exposure time effects. J. Aquatic Plant Manag., v. 30, p. 1-5, 1992.

PITELLI, R. A. Macrófitas aquáticas no Brasil, na condição de problemáticas. In: WORKSHOP DE CONTROLE DE PLANTAS AQUÁTICAS, 1998, Brasília. Resu mos... Brasília: Instituto Brasileiro de Meio Ambiente e dos Recursos Naturais Renováveis, 1998. p. $12-15$.

RYAN, F. J. Identification of monoecious and dioecious Hydrilla with the RAPD assay. Davis: USDA/Aquatic Weed Control Investigations, 1993a. p. 62 (Annual Report)

RYAN, F. J. Identification of monoecious biotype of Hydrilla with the RAPD assay. Davis: USDA/Aquatic Weed Control Investigations, 1993b. p. 60 (Annual Report)

SPRECHER, S. L.; GETSINGER, K. D.; STEWART, A. B. Selective effects of aquatic herbicides on sago pondweed. J. Aquatic. Plant Manag., v. 36, p. 64-68, 1998.

SOLYMOSY, S. L.; GANGSTAD, E. O. Nomenclature, taxonomy and distribution of Egeria and Elodea. Hyacinth Control J., v. 12, p. 3-5, 1974.

TANAKA, R. H. Eficácia de flu ridone para o controle de Egeria spp. em caix as d'água e em represa de pequeno porte sem flux o de água. $2001.51 \mathrm{f}$.

Diss ertação (Mestrado em Agronomia) - Universidade Estadual Paulista, Botucatu, 2001.

WEISS, A. Survey of Egeria densa accessions for genetic similarity by Random Amplified Polymorphic DNA analysis (RAPDs). Davis: USDA/Aquatic Weed Control Investigations, 1997. p. 69-73 (Annual Report)
YEO, R. R.; FALK, R. H.; THURSTON, J. R. The morphology of Hydrilla (Hydrilla verticillata (L. f.) Royle). J. Aquatic Plant Manag., v. 22, p. 1-17, 1984.

MARKING, L. L. Toxicity of chemical mixtures. In: RAND, G. M.; PETROCELLI, S. R. Fundamentals of aquatic toxicology. Washington, DC: Hemisphere Publishing, 1985. p. $164-176$.

MASCARENHAS, V. J.; GRIFFIN, J. L. Weed control interactions associated with Roundup and insecticide mixtures. In: DUGGER, P.; RICHTER, D. A. PROCEEDING OF BELTWIDE COTTON PRODUCTION RESEARCH CONFERENCE 1997, Memphis. Proceedings... Memphis: National Cotton Council, 1997. p. 799-800.

NASH. R. G. Synergistic phytotoxicities of herbicideinsecticide combination in soil. Weed Sci., v. 16, p. 74-77, 1968.

PANIZZI, A. R.; CORRÊA-FERREIRA, B. Dynamics in the insect fauna adaptation to soybean in the tropics.

Trends Entomol., v. 1, p. 71-88, 1997.

PANKEY, J. H. et al. Glyphosate - insecticide combination effects on weed and insect control in cotton. Weed Technol., v. 18, p. 698-703, 2004.

SCROGGS, D. M. et al. Glyphosate efficacy on selected weed species is unaffected by chemical coaplication. Weed Technol., v. 19, p. 1012-1016, 2005.

SILVA, M. T. B.; COSTA, E. C.; BOSS, A. Controle de Anticarsia gemmatalis Hübner (Lepidoptera: Noctuidae) com reguladores de crescimento de insetos. Ci. Rural, v. 33, p. $601-605,2003$.

YORK, A. C.; JORDAN, D. L.; FRANS, R. E. Insecticides modify cotton (Gossypium hirsitum) response to clomazone. Weed Technol., v. 5, p. 729-735, 1991.

WILLIAMS, T.; VALLE, J.; VIÑUELA, E. Is the naturally derived insecticide spinosad compatible with insect natural enemies? Bioc. Sci. Technol., v. 13, p. 459-475, 2003. 